The Geneva Papers on Risk and Insurance, 22 (No. 83, April 1997) 223-237

\title{
Insurance Markets and Climate Change
}

\author{
by Neil Doherty*
}

\section{Introduction}

The global climate has been changing over the ages. Variations in the earth's orbit with a cycle of about 90,000 years and tilts in the earth's axis over a cycle of about 41,000 years, are associated with ice ages and warming periods. At the other end of the time spectrum, sun spots can cause weather fluctuations measured in periods of a few years. Current concern with climate change has focused on the role of anthropogenic changes, notably the warming effects of increased carbon dioxide and other greenhouse gasses. Anthropogenic sources of such gasses are associated with industrialization and are estimated to have caused an increase in mean global surface temperature of about $0.45^{\circ} \mathrm{C}$ over the past century (IPCC-I, 1990, p. 198).

Alarm at this trend has led to intensive scientific and economic research aimed at forecasting the consequences of continued generation of greenhouse gasses, in terms of climate warming, sea level changes and the accompanying economic effects. Forecasting has been undertaken largely by means of general circulation models (GCM's) which model the interactive flows of air and water. Summarizing the results of these forecasts is possible. First, forecasts based on current natural and anthropogenic generation of GHG's and upon absorptive potential, suggest a continued increase in the atmospheric concentration of GHG's. Second, this concentration is associated with changes in two principle variables; an increase in mean global temperature and second an increase in mean sea level. Third, these forecasts are subject to very considerable uncertainty stemming from the wide margins of error inherent in each forecast, from differences in mean forecasts arising from different modelling methods and from intellectual disagreement between scientists. It is important to recognize that uncertainty itself is an important characteristic of our state of knowledge. Faced with these forecasts, scientists have charged themselves with a search for resolutions and ideas floated include re-forestation, energy substitution, fertilization of the oceans with iron, seeding the stratosphere with particles, as well as adapting to a warmer climate.

Global warming is also an economic phenomenon. Much of the generation of anthropogenic GHG's can be attributed to the externalization of costs from such activities as the burning of fossil fuels and the use of coolants in refrigeration systems. Moreover, the

* Wharton School, University of Pennsylvania. 
economic consequences of global warming are partly endogenous to the economic system. For example, increasing risk costs of locating in coastal areas will mitigate the current adverse migration to such areas, unless states subsidize such locations through tax incentives and underpriced insurance. For their part, economists have aimed at modelling the economic consequences including measuring the costs of controlling GHG's (Nordhaus 1991b); identifying the optimal level of generation of GHG's (Nordhaus 1991a) and proposing static policies such as energy and carbon taxes (Kaufman 1991; Oates and Portney 1992; and Viscusi et al, 1994) and adaptive models which allow policy to respond to new information (Nordhaus 1992, 1994, see also summary by Grubb 1993).

The effects of climate change on the insurance industry are potentially enormous. This subject has already been considered at length by others. ${ }^{1}$ Amongst the likely effects are an increase in hurricanes as ocean surface temperatures rise (Haarsma et al 1993). However this effect seems to be conditional on what happens to cloud cover as temperatures increase and cloud predictions are highly uncertain (Broccoli and Manabe 1990). These is also some prospect that, not only will hurricane frequency rise, but also severity (Emanuel 1987-1988). Predictions of changes in mid and high latitude storms seem to be more uncertain and while predictions have been made for specific locations, little generalization seems to be possible (see summary in Dlugolecki 1994, p. 33). For convective events such as tornados, thunderstorms and hailstorms, GCM models do seem to indicate increased activity (see summary in Dlugolecki 1004, p. 33) which again translates into potential increase in insurer claim frequency and/or severity. However, again changes in activity are likely to be location specific. Rising mean sea levels increase flood exposure for insurers even given current storm forecasts. However, the combined effects of more frequent/severe tropical storms, and higher sea levels are particularly disturbing. Finally, insurers can be affected in several other ways. Drought and frost also are sources of insurer claims for crop failure, burst pipes, etc. Moreover, climate change carries health implications which can impact on life and health insurance.

\section{Insurance markets for catastrophe risk}

\section{(i) Distribution and efficiency in an insurance system}

An insurance system distributes the random costs of individual losses across a pool of people. Absent inefficiencies, in the Pareto optimal scheme each person will substitute his/ her individial loss for a proportionate share of the aggregate losses of the whole community. This result (Borch, 1962) confirms a form of mutuality to insurance which is as extensive as possible. The "ideal" mutual is one covering all people and covering all types of risk. Indeed, Borch's result is exactly the same as (and precedes) that from the capital asset pricing model which shows that all should hold the market portfolio. The ideal "mutual" would cover both catastrophic and non catastrophic risk (and risk that is not thought of as insurable such as investment risk). Each policyholder would pay a premium equal to his/her expected loss plus a risk premium to allow for the degree of undiversifiable risk that each contributes. Thus, those policyholders not having catastrophe risk such as earthquake or hurricane potential, would pay only their expected costs (losses plus expenses). In contrast,

\footnotetext{
${ }^{1}$ See for example Dlugolecki, et al, IPCC which includes an excellent summary.
} 
those subject to catastrophe risk would pay expected costs plus a further amount determined by the correlation between their individual catastrophe loss and the aggregate loss (comparable to beta risk in the capital asset pricing model). This risk premium compensates those not having catastrophe risk for pooling their diversifiable risk with the non diversifiable catastrophe risk. Absent the risk premium, those without catastrophe risk would simply pool amongst themselves, rather than contaminate their pool with non diversifiable risk.

The second characteristic of an ideal insurance pool is that it encourages efficient use of scarce resources. In particular, decisions on safety and loss prevention should balance the costs and benefits at the margin. For example, choice of location of a home should balance all costs and benefits associated with that decision. Locating on a barrier island offers a number of obvious life style benefits but also it encounters high expected costs from storms and incursions of the sea. Similar issues apply to locating on the California coast with its climatic advantages but high earthquake risk. The costs of such homes should fully reflect, not only the expected costs of such damage, but also the risk premia associated with the provision of insurance. Similarly decisions on safety to existing structures should fully reflect costs and benefits. Thus, mitigation of potential storm damage to coastal homes, should balance the costs of such measures against the full reduction in the expected value of damage. To the extent that all insureds are charged the full value of their expected loss (including risk premia), and that premiums are fully adjusted to changes in expected loss, then insurance systems will encourage such efficient safety and preventative decisions. Insofar as premiums do not reflect expected losses, there will be underinvestment (or overinvestment)in prevention.

In a world of perfect information, the goals of risk sharing and efficiency are not in conflict. An universal insurance pool, covering all types of risk and with premiums set as described, would simultaneously lead to a Pareto optimal sharing of risk amongst a risk averse population, and would lead to socially efficient investment in safety.

\section{(ii) Issues in a static catastrophe insurance market}

Insurance functions effectively under a set of idealized conditions (see Berliner, 1982). Amongst these conditions, there should be a large number of independent exposures, all parties should be fully informed about the possibilities of loss. These conditions can be refined and supplemented to examine the condition of catastrophe insurance markets.

(a) Correlation amongst losses. Perhaps the defining characteristic of a catastrophe is that it affects a large number of people simultaneously. Events such as hurricanes and flood are of this nature. This means that the insurer cannot rely on the law of large numbers to produce stable financial results; in years without a catastrophe a profit may be earned and in years with a catastrophe a massive loss can be suffered. This situation can be alleviated by the design of the insurance contract or the insurance firm. Building on Borch's result, Marshall, 1974, and Doherty and Dionne, 1993, have shown that, absent the universal mutual concept, a mutualizing of insurance can be a sensible response to market failure. Mutual contracts divide risk into that which is diversifiable and that which is not. The non diversifiable risk is retained by the owners of the insurer, (i.e., the policyholders) in the form of dividends or assessments. Such retroactive adjustments would be related to premiums, which in turn reflect risk exposure. Now, since any catastrophe affects policyholders to different extents, then even a regional mutual offers significant risk spreading potential. For example, a mutual of Miami homeowners could be reasonably effective in equalizing the 
costs of a hurricane over its policyholders, even though they would all face big assessments should the hurricane arise. Were the mutual to be spread over different locations, it can take advantage of low correlation between hurricanes hitting Miami and, say Charleston, to spread risk even further. Naturally, this process is improved if the mutual then extends to different perils. However, a barrier to extending the mutual beyond narrow boundaries arises if the parties feel that pricing is unfair. And as information on which to base prices is unreliable, such feelings of inequity are not unlikely.

(b) Information and agency: imperfections and asymmetries. The first information problem that hinders private insurance markets is that loss distributions are not well specified. Insureds and insurers do not know the expected value of loss or its variance. Improved scientific models, have no doubt led to improved predictions, but it is still very difficult to make reliable estimates of even expected values (let alone variances) for losses such as hurricanes, floods and earthquakes. This deficiency has a dampening effect on insurance markets. Lack of knowledge fosters differing subjective estimates of loss. To the extent that many insureds hold lower estimates of expected loss than insurers, insurance will be seen as expensive and is unlikely to be purchased. This situation is promoted by casual appeal to statistical data. The infrequency of major catastrophes, particularly the rarity of such events at a single location such as "my house" encourages a small sample bias. Attitudes such as "I have been paying premiums all these years and not had a penny back" or "I haven't bought insurance for the last few years and nothing bad has happened" are frequent rationalizations for cancelling, or not buying, insurance.

(c) Corporate structure and reinsurance. The concept of a universal mutuality is an idealized one. The requirements of capital formation and the advantages of competition have led to an insurance system in which there are many firms with different organizational structures. This means that any substantial catastrophe is likely to fall with varying impact on different firms. Studies estimating the impact of two $\$ 7$ billion hurricanes (AIRAC 1986), or a repeat of the 1906 San Francisco earthquake (Doherty, Kleffner and Kunreuther 1992), have shown that some insurers would survive whereas others would become insolvent. And, in fact, events such as Hurricane Andrew (which cost the industry about $\$ 16.5$ billion). did indeed result on insolvencies.

The U.S. property liability insurance industry has a collective surplus over $\$ 200$ billion. In principle this amount should be available to pay for "unexpected" losses. Catastrophic losses are priced into insurance premiums. To the extent that the actual losses exceed premiums, surplus provides a buffer, and in this way, the owners of the insurer put their capital at risk. However, because of limited liability, many firms may become insolvent long before industry losses approach $\$ 200$ billion. Thus, the industry may not respond fully to even a $\$ 10$ billion or $\$ 20$ billion loss. This state of affairs arises because the industry is not perfectly diversified. However, there are mechanisms to spread the burden of catastrophe losses across all firms.

- Reinsurance can be used either as a reciprocal spreading device between primary insurers or as a mechanism for bringing in new capacity in the form of specialist reinsurers. The Borch equilibrium would have reinsurance being used to the extent that all insurers essentially hold the same portfolio, though the size of their exposures would depend on their differing levels of capital. In this equilibrium, a given catastrophe would fall relatively evenly on all insurers. If the unexpected loss was lower than industry 
surplus, all would be able to respond. As soon as the loss hit industry surplus, it would trigger simultaneous insolvencies for all. Such an arrangement would maximize the efficiency of potentially available capacity. However, markets fall short of this ideal.

- A second mechanism for maximizing the available capacity is by insolvency guarantee insurance. Surviving insurers meet the liabilities of insolvent insurers. In theory such a system could both maximize capacity and provide efficient incentives to insurers and policyholders for sound insurance practice. This would require that all insurers pay for their guarantee insurance protection in advance according to their levels of financial risk (e.g. along the lines of the pricing mechanism proposed by Cummins 1988). Accordingly, high risk and poorly managed companies would be penalized and would be forced to pass this cost on to their policyholders or cut back on business. This would give policyholders an incentive to avoid high risk firms. However, current schemes are based on ex post assessments on surviving insurers. Thus, unsound companies in fact can gain a short term price advantage and there is no incentive for policyholders to monitor their condition. This scheme echoes the dysfunctional incentives of the FSLIC that led to the "savings and loan crisis".

- The third mechanism for maximizing capacity, lies in using reinsurance substitutes. These potential alternatives are all the more important since catastrophe reinsurance markets have been quite unstable, with capacity fluctuating following major losses. ${ }^{2}$ Catastrophe futures, options on these futures, and financing instruments such as "act of god bonds" provide mechanisms for investors to provide risk capital against catastrophe risk (other than through the purchase of the equity of reinsurers). Insofar as such devices are bought and sold by insurers, they act like reciprocal reinsurance and can, in the limit, lead to the complete fungibility of aggregate industry surplus without it being increased. Alternatively, outside investors can supply such instruments which are then purchased by insurers. This pattern expands capacity. Another machanism is to use the state (i.e., taxpayers) to provide risk capital. Existing schemes (e.g., earthquake insurance in Japan and hurricane insurance in Florida) enlist the government as a reinsurer receiving premiums and paying for catastrophe claims. Currently, an insurance industry initiative, the National Disaster Coalition, is attempting to formulate a plan in which the Federal Government would assume such a role which would also be linked to mitigation. Finally, another prospect that has been examined is for the Federal Government to auction catastrophe instruments to insurers which, like catastrophe futures, would payout when an index of catastrophic losses exceeds some predefined trigger.

(d) Politicization and the demand for subsidies (ex ante and ex post). Insurance markets in many states have become politicized as consumers and taxpayers and special interest groups have identified opportunities to extract wealth either from each other or from insurance shareholders. This is apparent in automobile insurance market in which insurers are required to subsidize residual market plans, it is apparent in residual markets for catastrophe insurance and other attempts by state governments to require the provision of storm insurance in Florida or earthquake insurance in California. For example, in Florida, the residual market which was activated after Andrew, grew to be the third largest homeowners insurer

2 There may be a benign explanation for the withdrawal of capacity following shocks to surplus. Doherty and Posey 1995, suggest that such rationing would be predicted by incentive compatible contracts written under undiversifiable risk and asymmetric information. 
in the state. This remarkable growth has not come from entirely high risk individuals who could not obtain insurance in the voluntary market. Rather it is due, in large part, to the fact that residual market premiums were highly competitive with normal voluntary market premiums (which normally are of lower average risk). It may not be entirely a coincidence that the then insurance commissioner was running for the office of governor

Another form of subsidy is disaster relief in the form of low interest grants or loans. ${ }^{3}$ In principle the idea of disaster relief for events which are not predictable, is an attractive humanitarian gesture which has few adverse incentives. However, many disasters are in principle predictable and possibly insurable. The prospect of disaster relief by-passes the pricing system; instead of buying insurance and paying in advance according to expected losses, people are encouraged to rely on disaster relief. Not only does this discourage insurance, it also discourages mitigation.

\section{Global change and a dynamic catastrophe insurance market}

\section{(i) Possible increase in catastrophic losses}

The two main messages that come from the debate on climate change seem to be (a) that most experts predict that continued saturation of the atmosphere with GHG's will involve global warming and an increase in mean sea level and (b) that such predictions are surrounded with massive uncertainty both as to extent and timing. A secondary and weaker prediction is that there will be an increase in windstorm risk. This added prediction has profound implications for insurance markets. Increased storm activity (both severity and frequency) is associated with increases in ocean surface temperature. The time delays involved for such predictions are significant; ocean surface warming follows atmospheric warming with an estimated lag of two or three decades. The flooding implications are more clear. On a "business as usual" assumption for the generation of GHG's, the IPCC forecast is that mean sea levels would rise $66 \mathrm{~cm}$ between 1990 and 2100, (Cline 1991). A one meter rise would eliminate approximately $3 \%$ of land area; which in turn, involves a larger portion of cultivated area. Bearing in mind the concentration of population on the coasts, this would eliminate a large portion of populated land. Not only does the gradual inundation create flooding problems, but the perverse interaction of rising sea levels with possible increased tropical storm activity exposes large populations to the associated storm surges.

On best predictions, one can foresee a significant increase in global mean temperature, significant sea level rise and possibly a significant increase in tropical storm exposure, over the course of the next two or three or four decades. But, presently, the relentless migration to the coast continues. The long lifetime of the capital stock being assembled in such regions (homes, commercial and industrial developments, and other infrastructure investments) extends well into this forecast period. Accordingly, we can expect that the value of this capital will fall as the cost of these climate changes becomes apparent, or that its owners will be

3 The perception of such relief may be more important than its expected value. The actual relief is often not especially generous and is often attached to conditions (e.g., recent Mississippi flood victims were required to show three year's insurance purchase as a condition for relief. Some interviewees argued that they had been told that the 1995 floods were 1 in 100 year floods and, since they had similar floods a couple of years ago, they did not need to buy insurance since it wouldn't happen again in their lifetime). 
successful in enlisting political mechanism to protect its value through subsidized insurance or ex post disaster relief. Such high risk exposures will be commercially insurable only at high rates, and any attempt at rate suppression will lead to availability problems. Thus, one can forecast increased tension in insurance markets. In the meantime, either lack of recognition of the developing risk, or belief that the associated costs will be offset by subsidies from the low risk community, will artificially inflate the payback to investment in coastal property and infrastructure.

\section{(ii) Another source of risk: parameter uncertainty}

The time delays to achieve significant climatological changes are of the order of decades. In principle, this should give insurance markets, financial markets, and government planners time to adapt. As time goes by, we will improve our understanding of atmospheric and oceanographic processes as well as the economic processes that lead to the generation of GHG's and to our ability to respond. Forecasts will be refined on the basis of new knowledge and understanding. Time would appear to be on the side of insurance markets. Although we do not know now what prices to charge, or what mitigation conditions to insist on a precondition for insurance for the year 2030 or so, we will be much better informed as that time approaches. But this assumes our only uncertainty is in the mean value of the forecasts generated by equilibrium GCM models. Our understanding of the process by which we might approach the equilibrium is even less understood. The increase in GHG's represents a disturbance to an equilibrium general circulation system. The path to a new equilibrium requires an understanding of the process by which circulation patterns reconfigure. Even if one could predict with certainty the new long term equilibrium weather system for any given region, there would probably be increased short term unpredictability. This parameter risk creates great challenges for insurance, both in pricing and financial planning.

Parameter risk, particularly not knowing the expected cost, causes the following problem for insurance. Since the expected loss is unknown, any anticipated premium may turn out to be excessive or inadequate. Who should bear this risk? Should the insurer take this risk or should it be turned back to the insured in the form of a dividend or assessment based of the aggregate loss experience? The theory of Borch can be adapted to suggest that the mutualization of this parameter risk is Pareto optimal (see Doherty and Schlesinger 1995). With slow trends in losses, policyholders would bear the risk of changes in expected losses by changes in prepaid premiums (in the year 2019 we may well have a good idea of the premiums to charge for year 2020). The real problem is that the possible destabilization of circulation systems causes great uncertainty in the premiums to charge for the coming year, and prior statistics are quite fallible. The principle of mutualization suggests that policyholders bear this risk by dividend adjustment or assessment.

\section{Diversifying and mitigating risk in an era of climate change}

\section{(i) First objective: effective diversification}

The term "risk spreading" relates to the re-distribution of the costs of a catastrophe from those actually suffering loss to those who ex ante were commonly exposed to the risk of such loss. Risk spreading can be achieved in a direct or indirect manner (see Marshall 1976). In a direct manner, risk spreading takes the form of mutual insurance. Losses are allocated to those at risk either through the devices of (pre loss) premiums and (post loss) 
dividends. This process may be facilitated by the contribution of surplus by the policyholders. In their purest form, such mutuals offer only limited potential for spreading catastrophe risk, since they are confined only to those at risk. However, the possibility for extending the mutual to cross geographical boundaries and to cover other lines of insurance, significantly extends the risk spreading capacity. Indirect risk spreading spreads the risk beyond those who are exposed to peril, to specialized risk bearers (investors) who simply provide capital to hedge such risk. This can be achieved through a joint stock insurance form of organization, or by investors supplying other instruments that become payable in the event of defined catastrophes. The success of either form of risk spreading in hedging catastrophe risk depends on the ability to price according to full expected cost and on the level and fungibility of the capital supply.

Insurance systems work on one of two principles for spreading the costs of accidents. The first is that the costs of those suffering losses are spread over those commonly exposed to the possibility of loss. The redistribution takes place within a very limited time period and is essentially a cross-sectional redistribution. The second principle is that insurance spreads each individual's costs from random losses across time. Given a long enough time period, we would each pay for our own losses; but insurance would smooth the costs. This is intertemporal redistribution. Catastrophes are massive losses that reduce the total resources available to the community. Thus, the current population must bear the impact of those losses. The real question is, how is the burden spread across the population; insurance spreads it widely whereas no insurance lets the loss lie with those whose capital is destroyed. It is largely an illusion that we can, as a society, save for catastrophes. As individuals, we can save for rainy days by storing financial assets. But in the event of a catastrophe, many people liquidate these financial assets simultaneously to pay for their losses. This mass liquidation simply redistributes purchasing power against the given, but reduced, social wealth. It is simply a way of achieving a cross sectional spreading of the burden. We should recognize that our generation does pay for today's catastrophes; insurance does not directly cause inter-generational transfers. Thus, the social policy question to be addressed is how to spread the costs of actual catastrophes across the current population.

\section{(ii) Second objective: mitigation}

However, actual catastrophes are not entirely exogenous to our economic decisions. Loss mitigation has an inter-temporal dimension. The actual catastrophes that occur tomorrow, or at least their severity, are partly determined by today's decisions on safety. By investing in safety today, we can reduce the impact of tomorrow's catastrophes. Thus diverting today's consumption into safety investments (choosing low risk locations, tightening building standards, retrofitting existing structures for storm resistance, etc.), can mitigate losses. Such investments should be responsive to the usual social investment criterion; they should be undertaken up to the point that marginal social costs equal marginal social benefits. If the costs of catastrophes are externalized from the owners of capital, there will be an under-investment in safety.

It is useful to distinguish between ex ante moral hazard and ex post moral hazard. Mitigation can be achieved by pre-loss decisions such as relocating to a less hazardous area, or building to stricter codes. Appropriate incentives can be derived for such activity such as premiums that are sensitive to such investment. But losses can be mitigated after the fact. Protective action impending, during or after, can reduce loss. Examples are the use of 
shutters, quick removal of contents after structural damage to a building and the use of temporary fixes to avoid the abnormally high costs of building supplies and services in the period immediately following the disaster.

\section{(iii) Full cost pricing}

Risk spreading is an ex post redistribution of wealth. If risk spreading is to be distributionally neutral $e x$ ante, then all participants must be charged premiums that reflect the full expected cost of their individual loss, including any risk premium associated with such loss. I will refer to such pricing as full cost pricing, FCP.

The concept of FCP is important to the current discussion of risk spreading for two reasons. Absent FCP, opportunities for extensive risk spreading will be foregone. This occurs in two ways. First, the demand for insurance or hedging is determined by balancing the insurance premium with the risk characteristics (e.g., mean and variance) in accordance with the risk aversion of the participants. If insurance premia contain systematic subsidies across policyholders, the demand for insurance will be disturbed in a predictable fashion. For example, the equalization of premiums for high and low risk people, will lead to abnormally low demand for insurance for low risk types, and abnormally high demand from high risk types. The effect is similar to adverse selection and it will effectively deny insurance to those from whom subsidies are to be extracted.

The second way in which non-FCP depresses insurance trade is a supply side effect. The overall level of prices relative to overall risk determines the supply of insurance or insurance substitutes. If prices are abnormally low relative to known or expected risk, then investors will be unwilling to supply capital. While competition will eliminate insurance that is systematically underpriced, regulatory pressures often depress prices. Clearly this will lead to availability problems. In some markets (notably in catastrophe prone states in the U.S.), price suppression has depressed availability for current catastrophe risk and regulators have sought to tackle this by the short term expedient of denying rights of exit to extant insurers.

FCP also important for ex ante mitigation. Absent externalities, a hedging system that allocates the full expected cost of losses to each agent, will induce socially optimal mitigation decisions. Thus, in any insurance or other risk spreading system, the joint objectives of diversification and mitigation will be promoted by FCP. For ex post mitigation, other contractual incentives are required, such as stipulations as to post loss activity of the insured, or financial participation of the insured in the loss.

\section{(iv) Information constraints}

Full cost pricing is constrained by state of knowledge. We simply cannot specify the true and changing loss potential from climate change. Indeed, the loss potential in today's climate is quite uncertain and insurers have often been surprised by the magnitude of recent events such as Kobe, Northridge and Andrew. However, structural changes are occurring in the markets for information on the economic effects of catastrophes. Specialist firms such as R.M.S., E.Q.E. and others now produce analyses of the effects of major events such as windstorms, both in the U.S. and other parts of the world. This activity not only advances the frontiers of knowledge, but also can lead to an unbundling of risk management functions and promote the involvement of capital market players. This in turn will lead to the expansion of risk bearing capacity. The reason unbundling will be aided is that, until now, 
insurers have held a comparative advantage in assessing catastrophic loss potential. Moreover, investors have been somewhat shy in investing in insurance substitutes when they buy insurance stocks and have some confidence in the ability of insurers to price catastrophe risk. Now merchant banks can purchase information, offer instruments with catastrophe protection and price the catastrophe hedge as efficiently as insurers. Indeed, merchant banks are now amongst the clients of these information houses.

\section{(v) Externalities}

The value of individual assets derives partly from the inherent properties and partly from the social and economic infrastructure in which they are set. This creates a set of externalities. A home may be undamaged in a storm, but damage to the local environment (e.g. the destruction of recreational beaches) and infrastructure (power and related services) may severely depress its value. Moreover, damage to surrounding properties will impact its value. In this way, each asset damaged partly damages the community and its ability to function. But catastrophes also can create positive and negative externalities. An example of a negative externality is that, following a catastrophe, each damaged asset helps to bid up the price of building supplies and materials. Positive externalities arise when destruction of some productive asset creates excess demand for surviving assets. Thus, when one factory is destroyed, rivals can expect a boost in demand.

These externalities suggest that optimal mitigation will not be promoted simply by insurers adopting FCP and there is an appropriate role for government. It is plausible to suppose that these externalities will become a relatively larger component of social loss as the size of the catastrophe increases.

\section{(vi) Capital supply and limited liability}

The capacity of a market place to spread risk depends also on the organizational and contractual conditions under which hedging occurs. The current risk spreading structure for cat risk comprises primary insurers, (capitalized from investors or policyholders and normally bound by limited liability) and a set of vehicles for insurers to transfer that assumed risk to other risk carriers. These vehicles include reinsurance, asset liability management and other hedges for catastrophic risk such as cat futures and options. The limits of risk spreading reflect both the supply of capital to the primary and secondary risk bearers and the degree of fungibility of that capital. For example, the U.S. property liability insurance industry has a little over of $\$ 200$ billion of capital, but limited liability and insolvency imply that not all that capital would be accessible in the event of a major catastrophe. Extension of the risk spreading capacity requires both an increase in the supply of aggregate capital (either by increased insurance surplus of the supply of new capital market cat instruments) and that liabilities of risk bearers be limited according to their reasonable capacity to pay. Events such as Hurricane Andrew and the Northridge Earthquake did involve some insurer insolvencies, though to some extent policyholders were able to recover under the Insolvency Guarantee Schemes. But these were losses of approximately $\$ 17$ billion and $\$ 11$ billion to the insurance industry. Losses of between $\$ 50$ - $\$ 100$ billion are now feasible and, with climate change, we must anticipate the future possibility of larger, and more frequent losses. Such losses would overwhelm the insurance industry as it currently exists. Even the guarantee schemes would be overwhelmed as assessments on surviving insurers would simply lead to secondary defaults. 


\section{The design of a market for hedging}

(i) The role of insurers and capital markets

The two parametric features of catastrophe risk that emerge given predicted climate change are that expected losses are likely to be high and that there is a high variance of our forecast of expected losses. These features do carry implications for the design of an efficient hedging market. First, high mean and variance suggest that the amount and fungibility of capital supporting risk bearing be very large. To discuss the required expansion of capital and therefore capacity, consider Figure 1 . The bottom and left side show the structure of

Figure 1

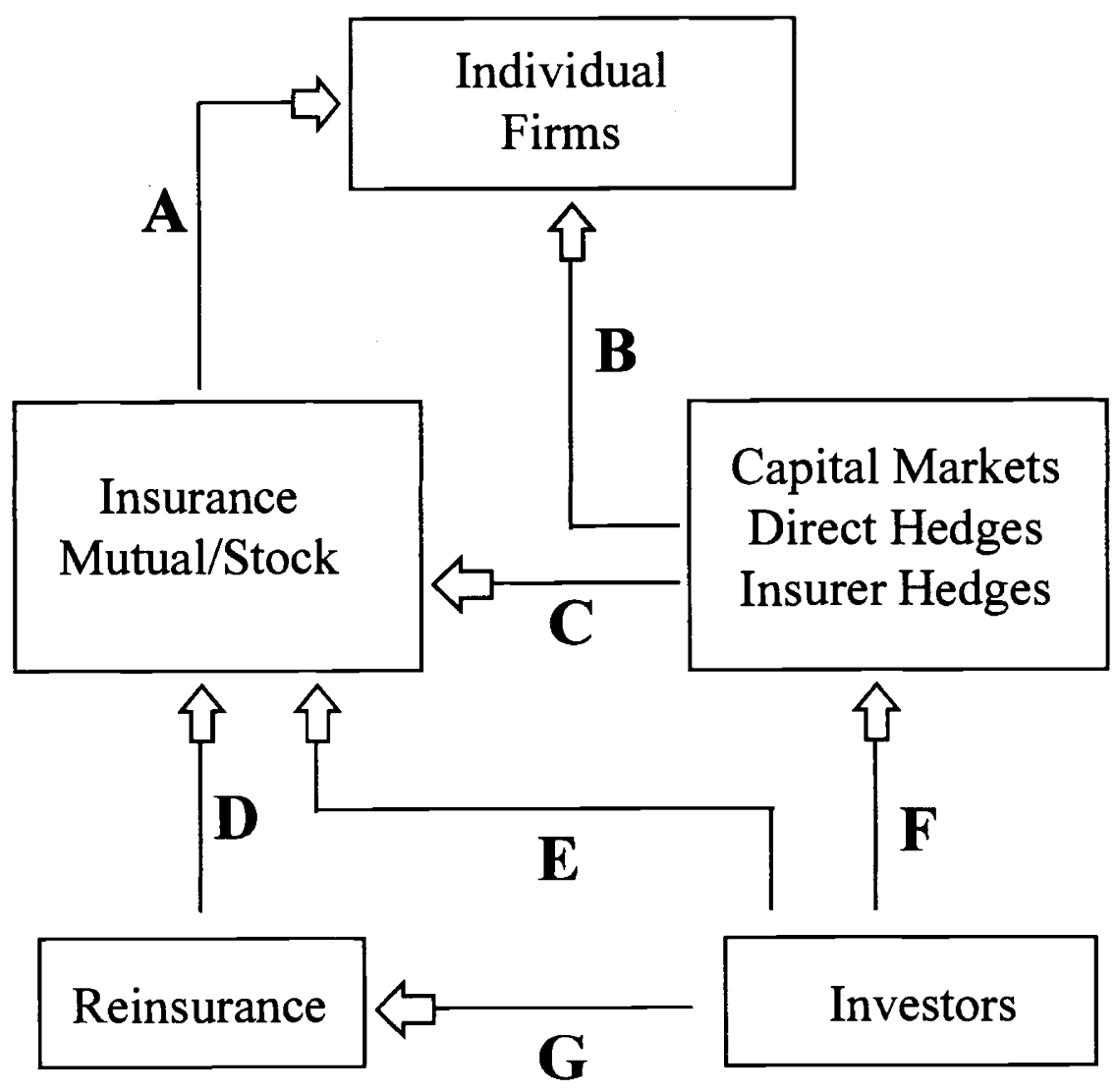


the conventional insurance industry. Investors supply capital to reinsurers (flow G) and insurers (E). Insurers offer insurance to individuals and firms (A), and hedge this loss by purchase of reinsurance (D). The expansion of capacity can be achieved by increasing flows through the insurance section of the diagram. Alternatively, investors might choose to bear catastrophe risk by purchasing catastrophe instruments offered through the capital market (F). Such instruments could be hedges offered directly to the public or to firms (B) such as Act of God bonds which forgive debt in the event of a defined catastrophe, or in the form of hedges to insurers $(\mathrm{C})$ such as catastrophe futures and options.

The existing catastrophe risk stretches the ability of the insurance industry to respond, and growth of this risk is unlikely to be met entirely from an expanded insurance industry. It is implausible that investors would wish to commit the massive surplus required to insure this risk, with an acceptable level of financial security (which in turn might imply rather conservative investment strategies for insurers). A more likely route is that the risk will be securitized, i.e., packaged in a standardized form in much the same way as current catastrophe futures and options. However, the basis risk of such standardized options is unlikely to make them attractive hedges for individuals and firms, but might be quite acceptable for insurers who hold portfolios. Moreover, there are still other services that need to be attached to, or sold alongside, basic hedges, such as claim settlement and mitigation. Thus, I would see a continuing role for insurance for individuals. However, I would see the main role of capital markets as providing either complements to, or more likely substitutes for, catastrophe reinsurance. The availability of such hedges to insurers could lead to a dramatic expansion of the effective capacity and fungibility of the insurance sector.

This expanded provision of insurer hedges that substitute for reinsurance depends on three conditions. First that appropriate pricing models be developed for such instruments. Just as option markets blossomed when an effective pricing model emerged (i.e., the Black Scholes model), so an effective pricing model for catastrophe options is a likely precondition for the growth of this market. Second, existing instruments have a serious credit risk problem which cannot be tackled by existing controls such as "mark to market". ${ }^{4}$ The credit risk is aggravated by the indivisibility of contracts and the small market. If, and when, similar instruments become divisible and available in large numbers the credit risk will be mitigated since they will become part of the market portfolio and included as a small component of the portfolios offered by many mutual funds. The third precondition is largely in place. Hedges often involve moral hazard. For example, reinsurance triggers a moral hazard problem. Primary companies will be more lax in underwriting new policies and in settling claims, if they have more reinsurance. These incentives may be countered by design features of the reinsurance contract (e.g. ex post assessments and long term commitments), but either way there is a loss of efficiency. The advantage of the catastrophe derivatives is that they avoid this moral hazard problem. If a primary insurer buys such derivatives, payout does not rest on that insurer's individual loss experience, but on a market index. Thus, moral hazard is largely avoided, at the cost of some basis risk.

\footnotetext{
${ }_{4}$ Under a mark to market system the net position under an option or future is adjusted daily according to price changes. This offers credit protection when prices evolve in a smooth fashion. But with catastrophes the index is flat at zero, until a catastrophe hits and the index jumps through the roof.
} 
Whilst the main role for capital markets in an expanded catastrophe market is likely to be in offering reinsurance substitutes, a secondary role is to provide direct instruments (flow $\mathbf{B}$ in Figure 1). Since the advantage of capital markets is their ability to securitize, and this introduces some basis risk, then it is unlikely that some derivative product will evolve which will appeal to households. However, some possibilities are apparent. One is a debt forgiveness instrument which might be attached to mortgages. Like an "Act of God" bond, such mortgage debt would have interest or principle forgiveness in the event of a major catastrophe. The lender might, in turn, strip out the debt forgiveness, and re-sell this to other investors. "Act of God" bonds, and other debt forgiveness ideas, are already being floated for commercial loans.

Thus, I would expect that capital markets would play a more important role hedging catastrophe risk as, and if, this grows with climate change, mainly in providing hedge products to insurers, but also in providing direct hedges or debt forgiveness products.

\section{(ii) Optimal risk sharing and mitigation}

The optimal design of hedging instruments is important. Instruments, whether provided by the insurance or capital markets, should offer partial protection; partial in two dimensions. First, they should mutualize the risk. As mentioned previously, this means that, while the hedge may payout according to the individual's actual loss, the individual's will be required to share in the undiversifiable risk by means of a dividend or assessment based on total loss. The nature of catastrophic risk is that it leads to a significant destruction of social wealth, and hedging should provide for an appropriate distribution of this real loss. This can be achieved by mutual forms of organization, by stock insurers using dividends or assessments or by natural economic mechanisms. A destruction of real resources will be followed by inflationary forces, particularly for those resources (building supplies and services) most affected by the disaster. This inflationary pressure will help re-distribute the cost of disaster over a wider population.

A second reason why the optimal form of hedging would appear to be a mutualization of the risk, relates to the parameter uncertainty surrounding expected losses. This parameter risk can be dealt with by the mutualization idea (see Doherty and Schlesinger 1996). To the extent that risk turns out to be higher than expected, it can be recovered in retrospective assessments levied on the population at risk.

A second influence on optimal insurance design is moral hazard. In principle, ex ante moral hazard will disappear with full cost pricing. However, the informational requirements for FCP are such that moral hazard is unlikely to disappear. For this reason, together with the need to address ex post moral hazard, the optimal contract design involves only partial hedging of the idiosyncratic risk of each individual. Thus second best policies or hedges, would have deductibles or coinsurance features in which each individual participated in the financing of his or her own loss.

Taken as a whole, major catastrophe risks are optimally hedged when each individual retains part of his/her own loss and shares in the overall social loss. This design feature is important to recognize when addressing the role of government.

\section{(iii) The role of government}

The usual economic rationalizations for government activity are based on externally or public good issues, or on the desire to redistribute income. There is a real externality issue involved in catastrophe; individual losses contribute to the destruction of the social and 
economic infrastructure. On the other hand individual losses also create demand for suppliers and competitors. A clear implication of these externalities is that privately provided incentives for mitigation are unlikely to be socially efficient. If the net externality is negative, then private incentives are likely to lead to under-investment in safety. Thus, one clear role for government lies in the re-dress of incentives. This could be achieved by taxes, by zoning or other means.

The distributional objective usually is one of equalizing income and addressing issues such as poverty. This objective is very different from providing properly priced insurance to secure ex post distributions to those suffering loss. One potential role that has been explored both in the U.S. and elsewhere is that of the government as an insurer, or reinsurer. Certainly, the risk bearing capacity is maximized with government insurance. However, government provision or regulation of insurance is often exposed to pressure to subsidize premiums for influential groups. Indeed, regulation in the U.S. has led to such subsidies to barrier island dwellers and to unprofitable residual markets for those unable to secure insurance in the private market. In other words, in providing insurance, governments will often seek re-distribute ex ante wealth in favor of favored groups. Such provision provides sub optimal incentives for mitigation.

In contrast to government provision, competitive provision of hedging instruments is likely to be disciplined by incentives for risk based categorization and pricing. In other words, private markets create incentives for unbiased use for loss information. To the extent that insurance is provided by private firms in competition with each other, this objective is likely to be met. Similarly, to the extent that risk capital is made available from capital markets, competition will again tend to eliminate contracts based on biased information. As mentioned, to the extent that governments provide insurance, they will be subject to pressure from interest groups that seek to minimize risk in order to secure subsidized insurance.

In defining a role for government, it is important to recognize that the optimal, second best, hedging contracts do not involve full insurance. Rather, because of moral hazard and undiversifiable risk, some idiosyncratic and social risk should be by those exposed to potential loss. Such risk sharing will promote the supply of risk borne capacity and improve incentive for mitigation.

While the argument favoring government provision of insurance is based on its huge risk bearing capacity, the potential expansion of capital markets into this arena also offers enormous risk bearing potential. Calls for the entry of the government as an insurer of last resort, such as the insurance industry sponsored bills in the U.S., may be premature. The bolstering of the insurance industry by the provision of insurer hedges and the potential supply of direct hedges by the capital markets, may indeed supply the capacity needed to hedge the growing catastrophe risk. 


\section{REFERENCES}

All-Industry Research Advisory Council (AIRAC), 1986, "Catastrophic Losses: How the Insurance System Would Handle Two \$7 Billion Hurricanes”, AIRAC, Oak Brook, Illinois.

BERLINER, B., 1982, Limits of Insurability of Risks, Prentice Hall, Englewood Cliffs, NJ.

BORCH, K., 1962, "Equilibrium in a Reinsurance Market”, Econometrica, 30, pp. 424-444.

BROCOLI, A. J. and MANABE, S., 1990, "Can Exisitng Climate Models be used to Study Anthropogenic Changes in Tropical Cyclone Climate?" Geophysical Research Letters, 17, pp. 1917-1920.

CLINE, W. R., 1991, "Scientific Basis for the Greenhouse Effect”, Economic Journal, 101, pp. 904-919.

DOHERTY, N. A., KLEFFNER, A. E. and KUNREUTHER, H., 1982, "Should Society Deal with the Earthquake Problem?", Regulation.

DOHERTY, N. A. and LIPOWSKI P., 1995, "Asymmetric Information and Availability Crises in Insurance Markets" working paper, Wharton School.

DOHERTY, N. A. and SCHLESINGER, H., 1995, "Severity Risk and the Adverse Selection of Frequency Risk", Journal of Risk and Insurance, forthcoming.

DLUGLECKI, A.F., CLARK, K. M., McCAULEY, D., PALUTIKOF, J. P. and YAMBI, W., 1994, "Working Group II: Impact of Climate Change", Chapter 9, Financial Services, IPCC Second Assessment Report.

EMANUEL, K. A., 1987, "The Dependence of Hurricane Intensity on Climate", Nature, 326, pp. $483-485$.

EMANUEL, K. A., 1987, “Towards a General Theory of Hurricanes", American Scientist, 76, pp. 371-379.

GRUBB; M., 1993, "Policy Modeling for Climate Change: The Missing Models", Energy Policy, March, pp. 203-208.

HAARMSA, R.J., MITCHELL, J. F. B. and SENIOR, C. A., 1993, "Tropical Disturbances in a GCM", Climate Dynamics, 8, pp. 247-257.

KAUFMAN, R. K., 1991, "Limits on the Economic Effectiveness of a Carbon Tax", The Energy Journal, 12, pp. 139-144.

NORDHAUS, W. D., 1991a, "To Slow or Not To Slow: The Economics of the Greenhouse Effect", Economic Journal, 101, pp. 920-937.

NORDHAUS, W. D., 1991b, “The Costs of Slowing Climate Change: A Survey”, Energy Journal, 12, pp. 37-65.

NORDHAUS, W. D., 1992, "Rolling the Dice: An Optimal Transition Path for Controlling Greenhouse Gasses", Quarterly Journal of Economics.

NORDHAUS, W. D., 1994, "Climate and Economic Development: Climate Past and Climate Change Future", Proceedings of the World Bank Annual Conference on Development Economics, 1993".

OATES, W. E. and PORTNEY, P. R., 1992, "Economic Incentives and the Containment of Global Warning", Eastern Economic Journal, 18, pp. 85-98.

VISCUSI, W. K., MAGAT, W. A., CARLIN, A. and DREYFUS, M. K., 1994, "Environmentally Responsible Energy Pricing”, The Energy Journal, 15, pp. 23-42. 